$\angle$ Research Square

\title{
Evaluation of wear and fracture strength of zirconia- based ceramics and metal-supported ceramics after treatment with the chewing simulator
}

\section{Yadel Hazır Tekin}

Gaziosmanpasa University, Faculty of Dentistry

Yeliz Hayran ( $\nabla$ yeliz_hayran@yahoo.com )

Gaziosmanpasa University, Dentistry Faculty https://orcid.org/0000-0002-8664-9083

\section{Research article}

Keywords: Fractures, Stress, Zirconium, Dental Restoration Wear, Simulation

Posted Date: June 1st, 2019

DOI: https://doi.org/10.21203/rs.2.9976/v1

License: (c) (1) This work is licensed under a Creative Commons Attribution 4.0 International License.

Read Full License 


\section{Abstract}

Background: The aim of this study was to evaluate the fracture resistance and wear amounts of different zirconia and metal-supported ceramics. Methods: Katana, Prettau, Zenostar, InCoris TZI, BruxZir and porcelain fused to metal (PFM) were used $(n=10)$. All samples were aged via thermal-cycling. Wear test was performed in chewing simulator. Occlusal wear was measured via a 3D laser-scanner. Fracture resistance of samples was determined via a universal testing machine. For statistics, One-Way ANOVA and Tukey were used. Results: PFM had the highest wear area, and differences among groups were significant. BruxZir, Zenostar, and InCoris TZI had lower wear than Prettau and Katana, but the differences were not significant. All groups had similar wear volume. Fracture resistance was significantly lower in Katana and PFM than Zenostar, InCoris TZI, and Prettau. The difference between Katana and PFM was significant. BruxZir samples were not broken even with the highest force applied. Conclusions: Monolithic zirconia ceramics showed superior wear behavior compared to PFM in terms of wear area; however 3D wear measurements were similar. Fracture resistance was also higher in zirconia except for Katana, which had the lowest value. BruxZir was the hardest material with the lowest wear and highest fracture resistance.

\section{Introduction}

Prosthetic dental treatments compensate functional, esthetic and phonetic deficiencies in partial or complete edentulousness. Although every aspect of tooth loss is quite important, esthetics, especially in female patients and younger populations, might have greater importance. Furthermore, 'Esthetics' in dentistry became an expression directly describe anterior teeth deficiency or dental problems related to anterior teeth [1]. The esthetic concerns of currently used porcelain-fused to metal (PFM) restorations lead to a search for more esthetic, biocompatible and metal-free materials which could mimic tooth color [2]. The development of ceramics was a response to this increasing demand [1]. The ceramics have several advantages over PFM which are mainly the biocompatibility, long-lasting color stability, chemical resistance, good abrasion resistance, fine work in detail, corrosion resistance, and low heat and electrical conductivity [3]. However, ceramic materials are fragile, have limited tensile strength and might lose their resistance to stresses over time which could limit long-term use [4].

The disadvantages of ceramics lead to a search for materials with higher fracture strength and toughness such as glass infiltrated ceramics, zirconia-supported alumina, lithium disilicate reinforced glass ceramics and dense sintered zirconia-based ceramics [5]. Among those, zirconia-based materials are more advantageous due to high fracture resistance and toughness along with high biocompatibility and low bacterial adhesion [6, 7]. Conventional cementation is also a significant advantage of zirconia crowns [8]. Even materials with the best physical properties may show some deterioration in the oral environment after prolonged use [9]. Thermal changes and saliva cause fatigue in materials [10]. Especially zirconia is aged in the presence of water $[11,12]$. Another major problem of zirconia and other metal-supported porcelain restorations is the cracking and breakage in the porcelain fused to the metal [13]. To overcome this drawback of zirconia, monolithic zirconia materials which can prevent breakage in 
porcelain and metal connection has been developed [14]. Stability, durability, and sturdiness of the zirconia-based materials come from its crystalline structure. Polycrystalline ceramics, such as zirconia, do not have a glazed glass matrix between the crystals. All crystals are densely packed into regular arrays and then sintered [15]. The dense crystal lattice reduces fracture progression $[6,15]$.

Different pressure and temperature values cause zirconia crystals to exhibit either cubic, tetragonal or monoclinic crystalline structure [3]. The transition between the phases leads to a significant volumetric change. This structural expansion leads to tensile forces and cracks in the ceramic, reducing the hardness and durability of the material $[16,17]$. In prosthetic restorations, zirconia in the tetragonal phase is preferred, but to keep the zirconia stable in the tetragonal phase, pure zirconia should be modified such as addition of compounds like magnesium, calcium, scandium, yttrium, neodymium or cerium $\left(\mathrm{CeO}_{2}\right)$, magnesium oxide $(\mathrm{MgO})$ or yttrium oxide $\left(\mathrm{Y}_{2} \mathrm{O}_{3}\right)[7,16,17]$. Even if the zirconia in the tetragonal phase is kept constant, a transition between the phases occurs depending on the long-term use. This process is called low-temperature degradation (LTD) and causes cracks in the material due to water leakage between the grains [18]. LTD occurs at different degrees in different types of zirconia, and the degree of degradation depends on factors such as grain size, stabilizer distribution and concentration $[13,18,19]$.

All prosthetic materials, including zirconia, are constantly exposed to water and rapid temperature changes in the oral environment. It is known that continuous water exposes increase fatigue and reduce the durability of the materials depending on the physical properties of the material [18-20]. Furthermore, Ra caused by chair-side occlusal adjustments or wear result from occlusal functions were found to be associated with phase transformation (PT) [21, 22]. Based on this fact, the aim of the present study was to determine the occlusal wear and fracture resistance of 5 yttria-stabilized tetragonal zirconia polycrystalline (Y-TZP) types of zirconia materials and $\mathrm{Ni}$-Cr alloy which is frequently used in routine clinical applications after one year use which was simulated by thermal cycling and chewing simulator.

\section{Material And Methods}

The present study evaluated the wear and fracture resistance of five different zirconia and PFM materials (Fig. 1).

\subsection{Preparation of the master cast}

Firstly, a master cast with an abutment tooth of a mandibular left first molar tooth (Ivoclar-Vivadent, Schaan, Liechtenstein) from an acrylic jaw was prepared. The tooth was prepared according to the preparation rules [23] with diamond burrs, and 360 degrees chamfer preparation with 16degrees total occlusal convergence was created. To ensure standardization of the cutting depth, the guide grooves were used to remove $2 \mathrm{~mm}$ tooth structure from the occlusal area and $1.5 \mathrm{~mm}$ from the other surfaces. Sixty metal duplicates from the prepared tooth were prepared from $\mathrm{Ni}-\mathrm{Cr}$ alloy via laser sintering.

\subsection{Preparation of the zirconia crowns}


Zirconia crowns were prepared via CAD/CAM (Yenamak D40, Yenadent, Istanbul, Turkey). The metal alloy duplicate was scanned via optic reader after the spray application (Labor O-Spray S\&S Scheftner GmbH, Mainz, Germany). Monolithic zirconia crowns (BruxZir, Glidewell, Newport Beach,CA), (Prettau, Zirkonzahn, Neuler, Germany), (Zenostar, Wieland Dental, Pforzheim, Germany), (Katana, Noritake, Nagoya, Japan), (InCoris TZI, Sirona, Bensheim, Germany) were designed based on scanned models. The number, type and design of the tooth to be restored was selected from the system. Anatomical formations such as the height of the tubercle and the depth of the central fossa were not processed, and the restorations were completed as occlusal coping to provide same occlusal morphology in the restorations. All restorations were prepared with $1.5 \mathrm{~mm}$ occlusal thickness and sintered and glazed according to the manufacturers' recommendations.

\subsection{Preparation of the PFM crowns}

PFM was prepared from Ni-Cr alloy and Vita porcelain (Vident, Vita Zahnfabrik, Bensheim, Germany) by lost-wax technique. A Ni-Cr alloy (Nickel 61.4 \%, Crom 25.9\%, Molenium 11 \%, Cilisium $1.5 \%$, Magnesium $0.02 \%$, Cobalt $0.02 \%$ ) was used. Metal thickness was $0.5 \mathrm{~mm}$, and $1 \mathrm{~mm}$ porcelain was fused to the metal. Then leveling and glazing was performed. Final restorations are having $1.5 \mathrm{~mm}$ occlusal thickness was prepared. Ten samples for each group, totally 60 samples, were prepared.

\subsection{Cementation}

Before the cementation, inferior of crowns were abraded with $50 \mu \mathrm{m} \mathrm{Al}_{2} \mathrm{O}_{3}$. All crowns were cleaned, dried, and primed before cementation. Then all crowns were cemented with a dual-cured resin cement (Panavia F 2.0, Kuraray Noritake Dental Inc., Osaka, Japan) on their respective master model.

\subsection{Thermal Cycling (TC)}

All crowns were kept 24 hours after cementation and then scanned with a 3D laser scanner (LAS-20, SD Mechatronic $\mathrm{GmbH}$, Munich, Germany) to observe the occlusal wear before and after the aging procedure. Scanning was performed in the same position and setting for each crown following the manufacturer's protocol. After baseline scanning of the occlusal surfaces, crowns were treated with thermal cycle device with 664 cycles a day for 15 days, totally 10000 cycles. The bath temperature was 5 $\triangle C-55 \unrhd C$, and the waiting time at each temperature was 60 seconds while the dwell time between two temperatures was 10 seconds. During thermal cycling, decreased water was compensated with small amounts without affecting the temperature of the water bath.

\subsection{Chewing simulator (CS)}

After TC, all crowns were loaded to the dual axis CS device (Chewing Simulator CS-4.2, SD Mechatronic $\mathrm{GmbH}$, Munich, Germany). CS has four sample holders and a fluid reservoir surrounding these holders and enables computer control of vertical/horizontal forces. A metal ball applied chewing forces under water irrigation to prevent overheating. Crowns were loaded with vertical and lateral $2 \mathrm{~mm}$ movements for 
240000 cycles corresponding one year [24]. The CS was set to Movement speed: $55 \mathrm{~mm} / \mathrm{sec}$, vertical/horizontal movement: $2 \mathrm{~mm}$, forward and reverse movement speed: $50 \mathrm{~mm} / \mathrm{sec}$, cycle frequency: $1 \mathrm{~Hz}$, force: $50 \mathrm{~N}$.

\subsection{Determination of occlusal wear}

After TC and CS, laser scanning was repeated for each sample (Fig. 2). The first and second scanning data obtained for each sample were transferred to the Geomagic Control program (Geomagic Control, 3D Systems Inc., Rock Hill, USA), which created a 3D image based on the scanning data. The images were equalized by cutting in a particular plane to display the areas exposed to abrasion. The individual areas of the occlusal wears in the first and second images of each sample were measured, and the difference was recorded as the occlusal wear area. Then first and second images were superposed, and the overlapped area exhibited different colors based on the color scale of the program (Fig. 2). A mean numeric value for each sample based on the color was calculated and recorded as the occlusal wear volume.

\subsection{Determination of fracture resistance}

All samples were subjected to an occlusal force with a loading device with maximal force $10000 \mathrm{~N}$ (AGSX 10, Shimadzu, Kyoto, Japan) until the point of breakage. The samples to be tested were placed on supports and stabilized. For the test, the force was applied to the central fossa of the crowns with a steel bar at right angles to the sample. The force was applied to start from ' 0 ' to the value which breaks the sample which was recorded as fracture resistance.

\subsection{Statistical analysis}

All data were presented either mean \pm SD or percentage as appropriate. IBM SPSS (IBM SPSS Statistics 20, IBM Co., Chicago, IL, USA) was used for statistical analysis. One Sample KS test was used for normality. Following One Sample KS test, One Way ANOVA followed by Tukey HSD was used for group comparisons. $\mathrm{P}<.05$ was considered statistically significant.

\section{Results}

Mean occlusal wear area and volume of the samples were shown in table 1. Occlusal wear area was higher in the PFM samples than those of all zirconia groups $(P<.05)$ (Fig. 1). Among the zirconia samples, the wear area was $1.29 \mathrm{~mm}^{2}, 1.77 \mathrm{~mm}^{2}, 1.85 \mathrm{~mm}^{2}, 2.23 \mathrm{~mm}^{2}$, and $2.37 \mathrm{~mm}^{2}$ for BruxZir, Zenostar, InCoris TZI, Prettau, and Katana, respectively. Though there were slight differences, wear values were found similar among the zirconia groups $(P<.05)$ (Fig. 1). The wear image of BruxZir was presented at Figure (Fig. 2). The wear image of In Coris TZI was presented at Figure (Fig. 3). The wear image of PFM was presented at Figure (Fig. 4). 
Volumetric measurement results of the Prettau was $4.37 \pm 5.01 \mathrm{~mm}^{3}$ which is the highest value among the zirconia groups, and the value of PFM was $3.07 \pm 2.37 \mathrm{~mm}^{3}$. The volume values of BruxZir, Zenostar, InCoris TZI, and Katana were $1.67 \pm 1.24 \mathrm{~mm}^{3}, 2.95 \pm 3.36 \mathrm{~mm}^{3}, 2.13 \pm 1.79 \mathrm{~mm}^{3}$, and $2.54 \pm 2.64 \mathrm{~mm}^{3}$, respectively. Though the values differ from each other, the differences were not statistically significant (P>.05) (Table 1, Fig. 1).

Fracture resistance values of the groups were significantly different $(P<.05)$. The highest amount of the force which is $10000 \mathrm{~N}$ applied could not break the BruxZir crowns indicating the resistance of the material. Apart from BruxZir, the highest fracture resistance was observed in the Prettau $(4760.2 \pm 266.3$ $\mathrm{N})$, InCoris TZI $(4699.8 \pm 257.88 \mathrm{~N})$, and Zenostar $(4489.2 \pm 679.53 \mathrm{~N})$ and the differences among these groups were insignificant $(P>05)$ however these values were significantly higher than those of the PFM $(3491.3 \pm 195.65 \mathrm{~N})$ and the Katana $(2401.5 \pm 456.24 \mathrm{~N})(\mathrm{P}<.05)$. Furthermore, the difference between PFM and Katana was also statistically significant $(P<.05)$ (Table 1, Fig. 1$)$.

\section{Discussion}

Zirconia has a wide range of use in dentistry due to its superior mechanical and esthetic properties, biocompatibility, and low bacterial adhesion [6, 7]. However, long-term use of zirconia might decrease the durability and sturdiness of the material due to the constant exposure of saliva and wetting and thermal changes $[16,17]$. Zirconia is a crystalline material which has three phases, and thermal changes in the oral environment caused by hot and cold food and beverages lead to shifting in phases and thus LTD in long-term $[11-13,18,19]$. The damage on the zirconia result from PT and LTD vary in zirconia with different grain size and stabilizers [13, 18-20]. However, the studies regarding the effect of saliva and occlusal function on current zirconia systems are lacking.

In this regard, the present study evaluated the fracture resistance and occlusal wear of five different $Y$ TZP zirconia types after 10000 cycles of thermal cycling and chewing stimulator corresponding a oneyear use [25]. The wear area results confirmed the durability and resistance of zirconia materials against $\mathrm{Ni}$-Cr alloy. However, the 3D analysis showed similar wear volume indicating that wear of zirconia extend to deep areas vertically more than the surface while Ni-Cr alloy exhibited shallow but wide wear. In terms of fracture resistance, BruxZir was the most resistant to fracture among all tested materials. The lowest values belonged to Katana in zirconia materials, and $\mathrm{Ni}-\mathrm{Cr}$ exhibited higher fracture resistance. Other zirconia materials showed similar fracture resistance.

The durability of the zirconia material is related to the PT and Yang, et al., recently reported that PT occurred within six months of use and depended on the zirconia type [22]. Lee et al., demonstrated that Ra was associated with increased PT and PT deteriorated the material and flexural strength [21]. Ra is an important factor affecting occlusal wear. However, Yang et al., reported no occlusal wear despite increased Ra and PT in the Katana zirconia material as a Y-TZP zirconia material [22]. Also, occlusal adjustments on the zirconia material which increase $\mathrm{Ra}$, cause stress in the occlusal surfaces and decrease toughness [26] which is also reported by Wongkamhaeng et al.[27]. They also suggested a 
relationship between PT and deep subsurface damage on occlusal surfaces of the BruxZir zirconia material as another Y-TZP material [27]. Flinn et al., also evaluated three types of Y-TZP and showed that Katana exhibited lower LTD compared to Prettau and BruxZir and flexural strength and durability of the materials changed in a similar pattern with LTD [28]. BruxZir and Prettau displayed lower fracture strength and broke during the artificial aging procedure while Katana had limited alterations in strength [28]. In contrast, in the present study, BruxZir and Prettau exhibited superior fracture resistance compared to Katana while occlusal wear area and volume were similar. Similarly, Sarikaya and Hayran, reported no fracture despite 5-year artificial aging in BruxZir and InCoris TZI zirconia material [29]. There was no fracture observed during the aging procedure in the present study either. A possible explanation for the difference might be the sample thickness which was $0.2 \mathrm{~mm}$ in Flinn et al. [28]'s study while it was 1.5 $\mathrm{mm}$ in Sarikaya and Hayran [29]'s reports and the present study.

As for Prettau, hydrothermal aging significantly increased PT and thus decreased flexural strength and fracture resistance [30]. Stawarczyk et al.[12], evaluated four types of zirconia including InCoris TZI and Zenostar and showed increased wear after both thermal and mechanical aging procedures. They also found that Ra was not associated with occlusal wear and none of the zirconia had decreased flexural strength after aging processes [12]. Alghazzawi et al. [31], on the other hand, reported increased Ra in zirconia materials after aging. Most of the studies evaluated flexural strength rather than fracture resintance [11, 28, 30-32]. Similar to Stawarczyk et al. [12], Flinn et al. [28, 30] demonstrated decreased flexural strength with aging in Prettau and BruxZir zirconia while Katana zirconia was not affected. Besides, Alghazzawi et al. [31], suggested a decrease in hardness and Young modulus of Zenostar and BruxZir zirconia while flexural strength remained unchanged after thermomechanical aging. Contrarily, Mota et al. [33], showed an increase in flexural strength of Prettau after thermal and mechanical aging along with an increase in PT. The alterations in zirconia material were not affected by the zirconia type. Ghazy et al. [34], showed that 5000 TC cycles and 1000000 CS cycles did not affect the fatigue strength of the Zirconzahn. In terms of the present results, zirconia types exhibited different fracture resistance. Katana had lower fracture resistance compared to Prettau, InCoris TZI, Zenostar which had similar resistance values. Interestingly, in contrast with Flinn et al.[28], BruxZir were resistant to fracture even with $10000 \mathrm{~N}$ forces. The composition of Y-TZP such as the stabilizer and grain size might differ among each other and the difference in composition, along with the fabrication process, such as sintering temperatures, affect physical and mechanical behavior of the materials and resistance to LTD.

Among the zirconia, as also observed in the present study, BruxZir was suggested to have superior physical properties and fracture resistance since it was indicated for patients with bruxism [29, 35]. As for Katana, studies reported resistance against aging and high physical properties such as low PT, high flexural strength even with $0.2 \mathrm{~mm}$ thickness [28, 30]. Also, Dikicier et al. [36] demonstrated that flexural strength and fracture strength of Katana zirconia increased with the thickness of the material (from 0.5 $\mathrm{mm}$ to $0.8 \mathrm{~mm}$ ) and both of them was not affected by aging. In contrast, despite samples with higher thickness, Katana exhibited lower features compared to other materials. As for Prettau, studies were reported lower features compared to Katana; $[28,30]$ however; the present results indicated greater features. When previously reported wear amounts of zirconia materials were examined as a whole, the 
aging methods, aging times or parameters were found to be different. It is not possible to make a complete comparison with the other studies because different materials were used to evaluate the amount of wear and different materials were used as an antagonist. The possible reason for the difference might be the different aging procedure used. As for InCoris TZI, studies reported decreased mechanical features after aging; however, the change was found clinically insignificant $[5,29]$. In terms of present results, the highest wear area was located in PFM, and all zirconia had lower wear compared to PFM.

However, though not significant, BruxZir, Zenostar and InCoris TZI showed lower wear compared to Prettau and Katana. 3D wear analysis was also compatible with wear area except for PFM, which had horizontal wear rather than vertical thus having a volume close to those of the zirconia materials. As for zirconia, Prettau had the highest 3D wear, and BruxZir had the lowest, although the difference was not statistically significant. Regarding fracture toughness, the highest force of the machine $(10000 \mathrm{~N})$ could not break BruxZir samples. InCoris TZI, Prettau and Zenostar exhibited higher fracture resistance compared to PFM and Katana. The lowest fracture resistance belonged to Katana samples. Altogether, the differences observed among the zirconia materials in the present study might result from the composition and sintering procedures.

When zirconia is subjected to water, water reacts with yttria and forms yttrium hydroxide which inhibits oxide as a stabilizer and induces phase transformation [37]. As an alternative mechanism, water disrupts zirconium-oxygen bonds, and movement of hydroxide ions induce stress in the crystals thus lattice defects and phase transformation occurs [20,32]. Also, apart from hydroxide ions, oxygen from water can also fill oxygen vacancies present in the crystals [38]. Cotes et al. [39] demonstrated that 400 days of water expose significantly increased PT and autoclave aging also result in similar changes [40]. Also evaluated thermal and mechanical cycling and found that fracture strength of polished and glazed Y-TZP zirconia was not affected by 2500000 aging cycles. The present study used an artificial aging model with 240000 cycles of CS and 10000 cycles of TC which provide both thermal and mechanical stimulus. Various studies reported different aging models ranging from 5 hours to 1200000 cycles $[11,22,26,29]$. Steam autoclave aging was also used for artificial aging; [28,32] however, TC is more preferred to mimic oral conditions and provide LTD $[11,26,29,39]$. 10000 cycles corresponding to 1-year use might not be considered as long-term use, and studies reported 5-year simulations of use; [29] however, Yang et al. [22] demonstrated that six months clinical use of zirconia caused PT and occlusal wear and PT differences among the materials could be detectable in this period. Furthermore, Gale and Darvell [25] evaluated the TC and suggested that a 1-year simulation with 10000 cycles would be beneficial mimicking oral conditions.

\section{Conclusions}

Occlusal adjustments applied to the surface of the zirconia material increase the surface roughness and the aging on the material and consequently increase the phase transformation, and glaze reduces this effect. Since the effect of the glaze is temporary, aging and durability will be reduced in zirconia in long- 
term clinical use. Among different zirconia types, the degree of this LTD would be different, and the selection of the type of zirconia that is less affected by aging will be advantageous in long-term use. The present results showed that BruxZir of all tested materials exhibited optimal results in wear area and volume and fracture resistance. Other zirconia materials apart from Katana showed similar wear and fracture resistance while Katana had higher wear volume and lower fracture resistance even observed with the PFM.

Nonetheless, the results of this study should be interpreted considering certain limitations. Firstly, this study was an in vitro study and involving clinical results of zirconia materials would be beneficial. Secondly, five types of zirconia which were prepared as $1.5 \mathrm{~mm}$ thickness were tested. Additional materials with different thickness should also be evaluated. Third and lastly, the present study used only to wear area, volume, and fracture resistance. Other parameters such as phase characterization, phase analysis, flexural strength, etc. would provide further insight.

\section{Abbreviations}

\%: Percent; 3D: 3-Dimentional; CS: Chewing Simulator; g: Gram; h: Hour; Hz: Hertz; LTD: Low-temperature degradation; min: Minute; ml: Milliliter; mm: Millimeter; N: Newton; Ni-Cr: Nikel-Crom; Sec: Second; PFM; Porcelain fused to metal, PT: Phase transformation; Ra: Surface roughness; TC: Thermal Cycling; Y-TZP: Yttria-stabilized tetragonal zirconia polycrystalline.

\section{Declarations}

Acknowledgements

Not applicable.

Funding

This study was supported by 2015/63 number project by the Tokat Gaziosmanpasa University Scientific Research Projects Unit with the used materials. This study has been supported by only materials used in the study by Tokat Gaziosmanpasa University Scientific Research Projects Unit. Any financial support has not been provided for publication of the study results.

Availability of data and materials

Dr. Y.H. should be contacted if someone wants to request the data or material.

Authors' contributions

Y.H.T; Study conception and design, Acquisition of data, Analysis and interpretation of data,. Drafting of manuscript. Y.H.; Study conception and design, Acquisition of data, Analysis and interpretation of data, Critical revision. All authors read and approved the final manuscript. 
Ethics approval and consent to participate

Human subjects, human material, or human data, have not been used in this research article. So, the Declaration of Helsinki, and an ethics committee consent have not been referring provided.

Consent for publication

Not applicable.

Competing interests

The authors declare that they have no competing interests.

\section{References}

1. Christensen GJ. Choosing an all-ceramic restorative material: porcelain-fused-to-metal or zirconiabased? J Am Dent Assoc. 2007;138:662-65.

2. Kelly JR, Nishimura I, Campbell SD. Ceramics in dentistry: historical roots and current perspectives. J Prosthet Dent. 1996;75:18-32.

3. Anusavice KJ, Shen C, Rawls HR. Dental Ceramics. In: Anusavice KJ, Shen C, Rawls HR, editors. Phillips' science of dental materials, USA: Saunders Company; 2013. p. 418-74.

4. Wiskott HW, Nicholls JI, Belser UC. Stress fatigue: basic principles and prosthodontic implications. Int J Prosthodont. 1995;8:105-16.

5. Stawarczyk B, Özcan M, Schmutz F, Trottmann A, Roos M, Hämmerle CH. Two-body wear of monolithic, veneered and glazed zirconia and their corresponding enamel antagonists. Acta Odontol Scand. 2013;71:102-12.

6. Piconi C, Maccauro G. Zirconia as a ceramic biomaterial. Biomaterials 1999;20:1-25.

7. Tinschert J, Natt G, Mautsch W, Augthun M, Spiekermann H. Fracture resistance of lithium disilicate-, alumina-, and zirconia-based three-unit fixed partial dentures: a laboratory study. Int J Prosthodont. 2001;14:231-8.

8. Ernst $\mathrm{CP}$, Cohnen $\mathrm{U}$, Stender $\mathrm{E}$, Willershausen $\mathrm{B}$. In vitro retentive strength of zirconium oxide ceramic crowns using different luting agents. J Prosthet Dent. 2005;93:551-8.

9. Kwon MS, Oh SY, Cho SA. Two-body wear comparison of zirconia crown, gold crown, and enamel against zirconia. J Mech Behav Biomed Mater. 2015;47:21-8.

10. Rabinowicz E, Tanner R. Friction and wear of materials. J Appl Mech. 1966;33:479. 
11. Oyafuso DK, Özcan M, Bottino MA, Itinoche MK. Influence of thermal and mechanical cycling on the flexural strength of ceramics with titanium or gold alloy frameworks. Dent Mater. 2008;24:351-6.

12. Stawarczyk B, Frevert K, Ender A, Roos M, Sener B, Wimmer T. Comparison of four monolithic zirconia materials with conventional ones: Contrast ratio, grain size, four-point flexural strength and two-body wear. J Mech Behav Biomed Mater. 2016;59:128-38.

13. Sundh A, Sjogren G. Fracture resistance of all-ceramic zirconia bridges with differing phase stabilizers and quality of sintering. Dent Mater. 2006;22:778-84.

14. Guess PC, Schultheis S, Bonfante EA, Coelho PG, Ferencz JL, Silva NR. All-ceramic systems: laboratory and clinical performance. Dent Clin North Am. 2011;55:333-52, ix.

15. Giordano R, McLaren EA. Ceramics overview: classification by microstructure and processing methods. Compend Contin Educ Dent. 2010;31(9):682-4.

16. Pandoleon P, Kontonasaki E, Kantiranis N, Pliatsikas N, Patsalas P, Papadopoulou L, et al. Aging of 3Y-TZP dental zirconia and yttrium depletion. Dent Mater. 2017;33:e385-e92.

17. Zhang Y, Kim J-W. Graded structures for damage resistant and aesthetic all-ceramic restorations. Dent Mater. 2009;25:781-90.

18. Kohorst P, Borchers L, Strempel J, Stiesch M, Hassel T, Bach FW, et al. Low-temperature degradation of different zirconia ceramics for dental applications. Acta Biomater. 2012;8:1213-20.

19. Kim JW, Covel N, Guess P, Rekow E, Zhang Y. Concerns of hydrothermal degradation in CAD/CAM zirconia. J Dent Res. 2010;89:91-5.

20. Lange F, Dunlop G, Davis BI. Degradation during aging of transformation-toughened ZrO2-Y2O3 materials at $250^{\circ} \mathrm{C}$. J Am Ceram Soc. 1986;69:237-40.

21. Lee JY, Jang GW, Park II, Heo YR, Son MK. The effects of surface grinding and polishing on the phase transformation and flexural strength of zirconia. J Adv Prosthodont. 2019;11:1-6.

22. Yang SW, Kim JE, Shin Y, Shim JS, Kim JH. Enamel wear and aging of translucent zirconias: In vitro and clinical studies. J Prosthet Dent. 2019;121:417-25.

23. Hobo S, Shillingburg HT, Jr. Porcelain fused to metal: tooth preparation and coping design. J Prosthet Dent. 1973;30:28-36.

24. Beuer F, Stimmelmayr M, Gueth JF, Edelhoff D, Naumann M. In vitro performance of full-contour zirconia single crowns. Dent Mater. 2012;28:449-56.

25. Gale M, Darvell B. Thermal cycling procedures for laboratory testing of dental restorations. J Dent. 1999;27:89-99. 
26. Lai X, Si W, Jiang D, Sun T, Shao L, Deng B. Effects of small-grit grinding and glazing on mechanical behaviors and ageing resistance of a super-translucent dental zirconia. J Dent. 2017;66:23-31.

27. Wongkamhaeng K, Dawson DV, Holloway JA, Denry I. Effect of Surface Modification on In-Depth Transformations and Flexural Strength of Zirconia Ceramics. J Prosthodont. 2019;28:e364-e75.

28. Flinn BD, Raigrodski AJ, Mancl LA, Toivola R, Kuykendall T. Influence of aging on flexural strength of translucent zirconia for monolithic restorations. J Prosthet Dent. 2017;117:303-9.

29. Sarıkaya I, Hayran Y. Effects of dynamic aging on the wear and fracture strength of monolithic zirconia restorations. BMC Oral Health. 2018;18(1):146.

30. Flinn BD, Mancl LA, Raigrodski AJ. Accelerated aging characteristics of three yttria-stabilized tetragonal zirconia polycrystalline dental materials. J Prosthet Dent. 2012;108:223-30.

31. Alghazzawi TF, Lemons J, Liu PR, Essig ME, Bartolucci AA, Janowski GM. Influence of lowtemperature environmental exposure on the mechanical properties and structural stability of dental zirconia. J Prosthodont. 2012;21:363-9.

32. Alghazzawi TF, Janowski GM. Correlation of flexural strength of coupons versus strength of crowns fabricated with different zirconia materials with and without aging. The J Am Dent Assoc. 2015;146:90412. e1.

33. Mota YA, Cotes C, Carvalho RF, Machado JP, Leite FP, Souza RO, et al. Monoclinic phase transformation and mechanical durability of zirconia ceramic after fatigue and autoclave aging. $J$ Biomed Mater Res B Appl Biomater. 2017;105:1972-7.

34. Ghazy MH, Abo Madina MM, Aboushelib MN. Influence of fabrication techniques and artificial aging on the fracture resistance of different cantilever zirconia fixed dental prostheses. J Adhes Dent. 2012;14:161.

35. Renjo MM, Ćurković L, Štefančić S, Ćorić D. Indentation size effect of Y-TZP dental ceramics. Dent Mater. 2014;30:e371-e6.

36. Dikicier S, Ayyildiz S, Ozen J, Sipahi C. Influence of core thickness and artificial aging on the biaxial flexural strength of different all-ceramic materials: An in-vitro study. Dent Mater. J 2017;36:296-302.

37. Pereira G, Venturini A, Silvestri T, Dapieve K, Montagner A, Soares F, et al. Low-temperature degradation of Y-TZP ceramics: a systematic review and meta-analysis. J Mech Behav Biomed Mater. 2016;55:151-63.

38. Chevalier J, Gremillard L, Virkar AV, Clarke DR. The tetragonal-monoclinic transformation in zirconia: lessons learned and future trends. J Am Ceram Soc. 2009;92:1901-20. 
39. Cotes C, Arata A, Melo RM, Bottino MA, Machado JP, Souza RO. Effects of aging procedures on the topographic surface, structural stability, and mechanical strength of a ZrO2-based dental ceramic. Dent Mater. 2014;30:e396-404.

40. Lameira DP, De Souza GM. Fracture strength of aged monolithic and bilayer zirconia-based crowns. Biomed Res Int. 2015;2015:418641.

\section{Tables}

Table 1: Fracture resistance, wear area and volume in the study groups.

\begin{tabular}{|c|c|c|c|}
\hline $\begin{array}{l}\text { Parameters/ } \\
\text { Groups }\end{array}$ & $\begin{array}{l}\text { Wear Area } \\
(\mathrm{mm} 2)\end{array}$ & Wear Volume (mm3) & Fracture resistance $(\mathrm{N})$ \\
\hline $\begin{array}{l}\text { PFM } \\
\text { (Ni-Cr+Vita porcelain) }\end{array}$ & $4.59 \pm 1.55(\mathrm{a})$ & $3.07 \pm 2.37$ & $3491.3 \pm 195.65(x)$ \\
\hline Incoris Tzi & $1.85 \pm 0.98(b)$ & $2.13 \pm 1.79$ & $4699.8 \pm 257.88(y)$ \\
\hline Prettau & $2.23 \pm 1.33(\mathrm{~b})$ & $4.37 \pm 5.01$ & $4760.2 \pm 266.3(y)$ \\
\hline Katana & $2.37 \pm 2.16(b)$ & $2.54 \pm 2.64$ & $2401.5 \pm 456.24(\mathrm{z})$ \\
\hline Zenostar & $1.77 \pm 1.97(b)$ & $2.95 \pm 3.36$ & $4489.2 \pm 679.53(\mathrm{y})$ \\
\hline Bruxzir & $1.29 \pm 1.07(b)$ & $1.67 \pm 1.24$ & - \\
\hline
\end{tabular}

*One way ANOVA and Tukey HSD test was used for multiple comparisons. Different letters indicate statistical significance $(P<.05)$. No difference was observed in the wear volume.

\section{Figures}




\section{Groups and Parameters}

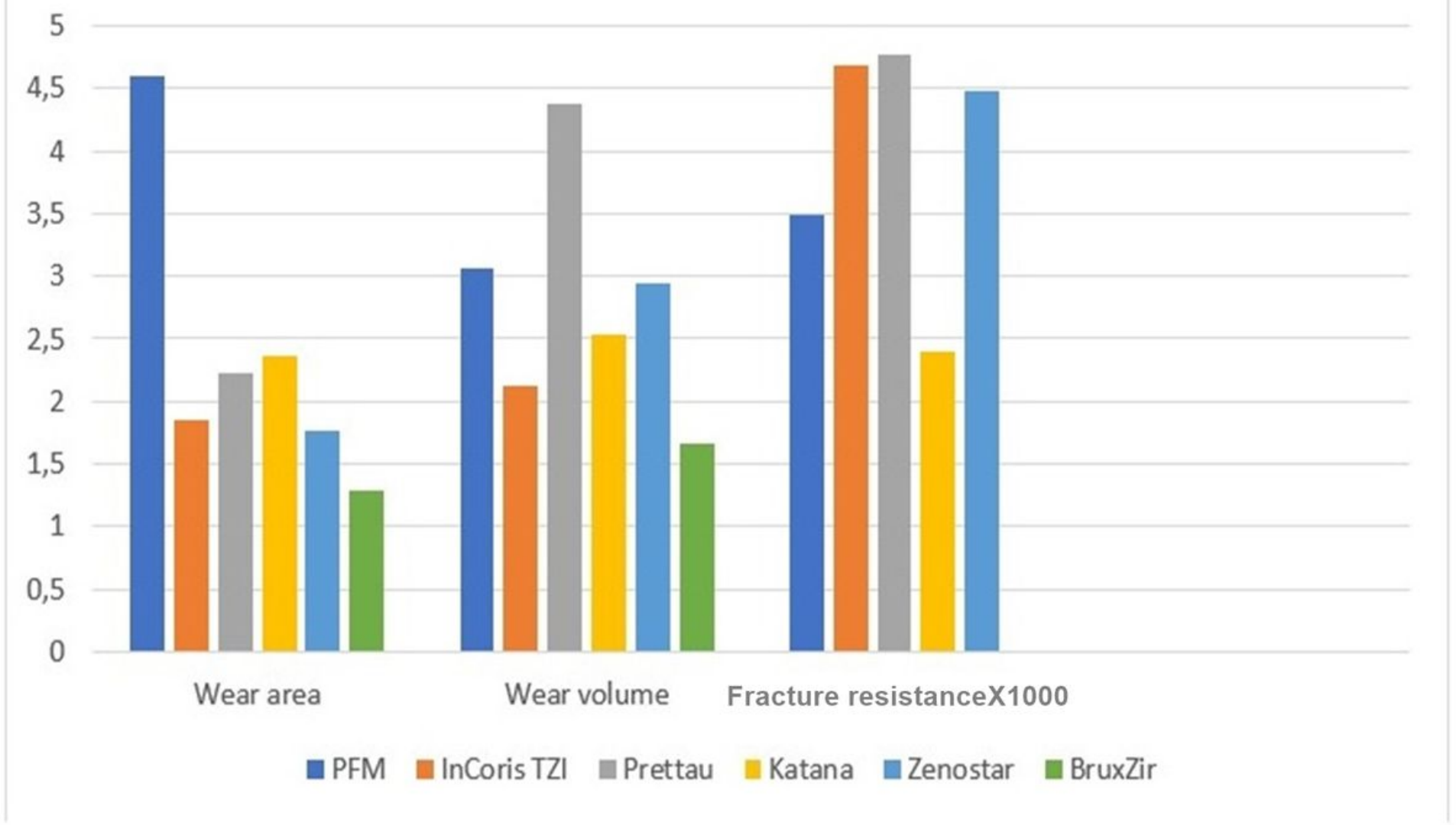

\section{Figure 1}

Graphic demonstrations of zirconia types, wear area, volume and fracture resistances of the study. PFM: Porcelain fused to metal ( $\mathrm{Ni}-\mathrm{Cr}+\mathrm{Vita}$ porcelain). 

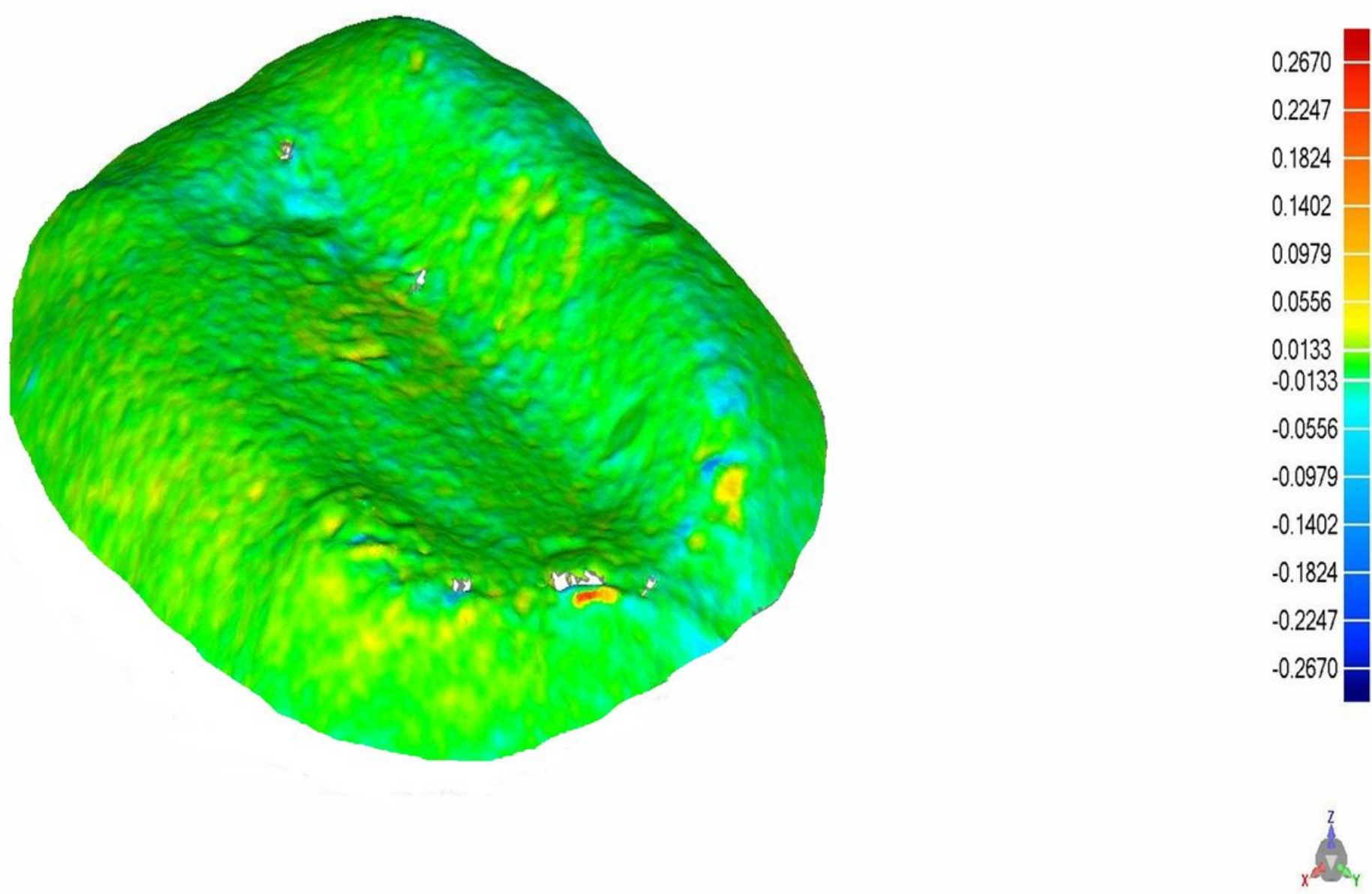

Figure 2

Wear images of the BruxZir 

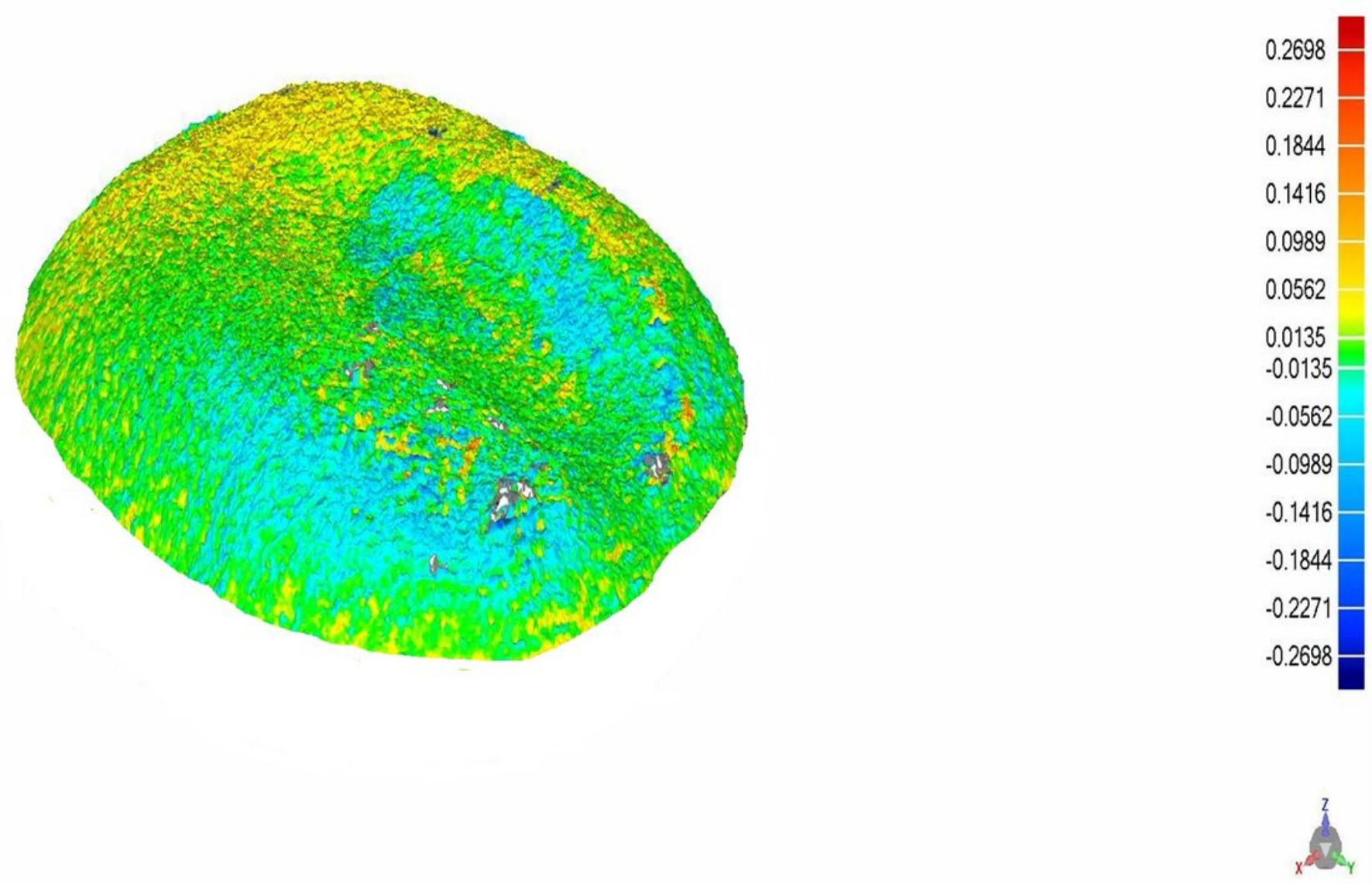

\section{Figure 3}

Wear images of the InCoris TZI 

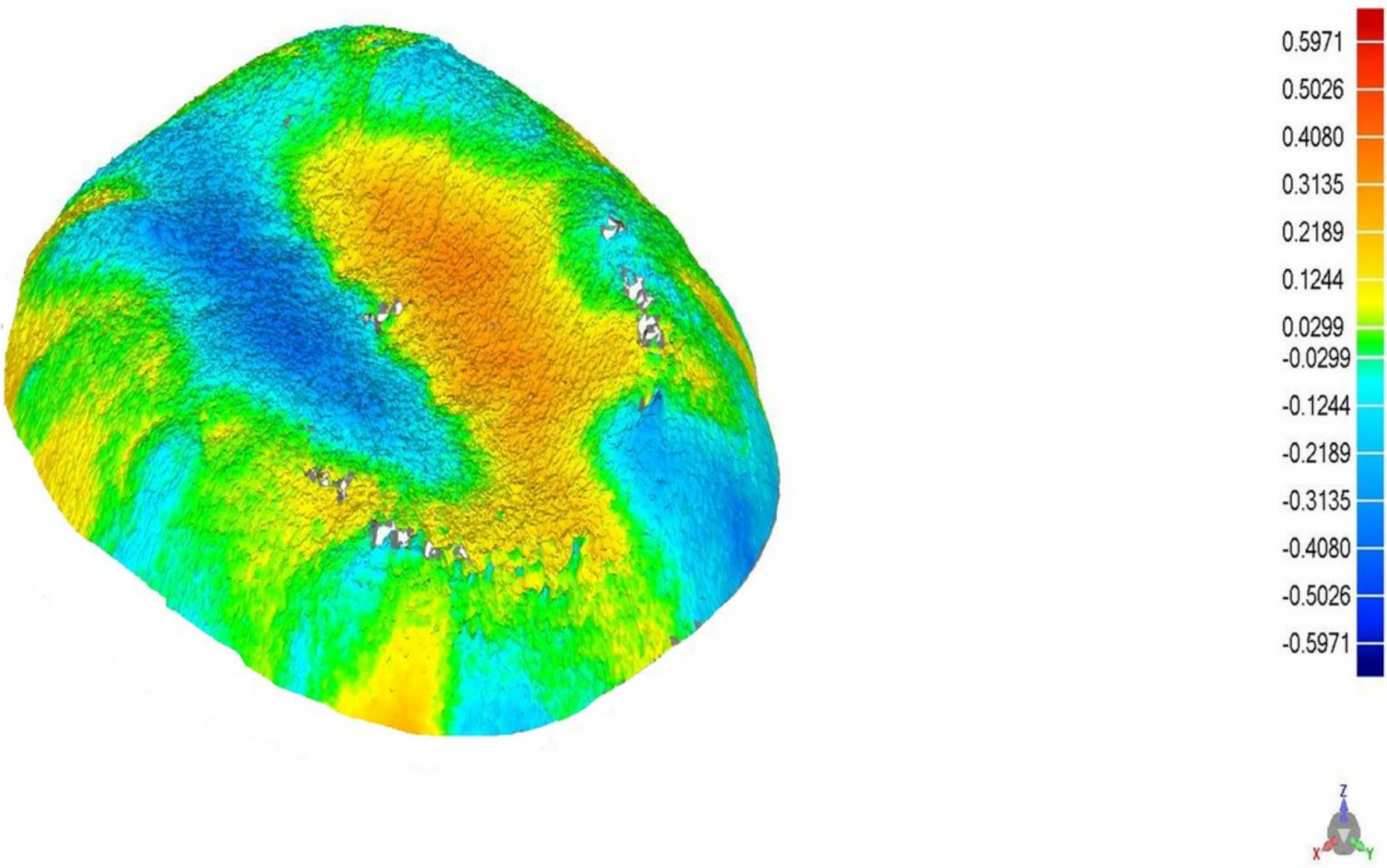

Figure 4

Wear images of the PFM. PFM: Porcelain fused to metal (Ni-Cr+Vita porcelain). 